\title{
ПЕДАГОГИЧЕСКАЯ ПСИХОЛОГИЯ
}

УДК 37.035

\section{РЕБЕНОК С ОВЗ В ПРИЕМНОЙ СЕМЬЕ: ОСОБЕННОСТИ ПСИХОЛОГО-ПЕДАГОГИЧЕСКОГО СОПРОВОЖДЕНИЯ*}

\author{
Л.Б. Шнейдер
}

ФГБОУ ВО «Московский государственный педагогический университет», Москва

\begin{abstract}
Обсуждаются вопросы устройства ребенка сопровождающиеся изменением его статуса, децентрацией восприятия себя как ребенка-сироты и обретением новой самоидентификации в качестве домашнего ребенка. Процесс усыновления ребенка рассматривается как период опасений, надежд, ожиданий и иллюзий. Подчеркивается, что суть психологопедагогического сопровождения ребенка заключается в необходимости смещения внимания замещающей семьи (её педагогической направленности) с факта ограниченных возможностей здоровья (ОВ3) приемного ребенка, с «жалостливого» и инвалидизирующего отношения к нему на создание условий для воспитания его как счастливого человека. Раскрывается представление о компетентном варианте родительства.
\end{abstract}

Ключевые слова: ребенок, сирота, нездоровье, приемная семья, трудности, надежды, счастье.

Переход любого ребенка из казенного (государственного) учреждения в приемную семью порождает множество опасений, надежд, ожиданий и иллюзий. Если в семью перемещается ребенок с OB3, то все эти проявления возрастают десятикратно. Во-первых, опасения (тревогу, беспокойство и пр.) порождает повышенная степень ответственности. Неумолимо накатывает волна сомнений: а вдруг не справимся? Сумеем ли? Не пожалеем ли потом?

Во-вторых, возникают надежды и ожидания, связанные как с внешними обстоятельствами, так и с внутренним самоуважением. Если не я, то кто же еще? Надежды возлагаются на саму смену обстановки, не зря же говорят, что дома и стены помогают (лечат). Улучшение в соматической картине заболевания(й), в психическом состоянии ребенка, возможно, не замедлит обнаружиться. Внутреннее самоощущение членов приемной семьи, которое подпитывается

\footnotetext{
* Работа выполнена при поддержке грантом РФФИ, научный проект №20-013-00654 «Педагогические условия повышения профессиональной компетентности педагогов в области психолого-педагогического сопровождения детей с ограниченными возможностями здоровья».
} 
благородством поступка, самоуважением, жалостью и вниманием к ребенку приглушает страхи, порождает готовность действовать, помогать, защищать, преодолевать. Не боги же горшки обжигают, в конце-то концов! Все это понятно, личностный, ситуативный и иллюзорный контексты нередко таких эмоциональных намерений и вытекающих из них последствий явственно проступают. Если надежды, смешанные с иллюзиями, превзойдут опасения, то выбор будет сделан в пользу усыновления.

Объективно в акте любого усыновления есть три ключевых момента: 1) сам ребенок, имеющий статус и самоидентификацию «сирота», и его особые потребности, связанные с ограниченными возможностями его здоровья; 2) замещающие родители (приемная семья), их жизненный опыт и воспитательный потенциал; 3) процесс принятия такого ребенка и включения его в новую для него среду обитания, конструирование целевой педагогической направленности воспитания и его технологического обеспечения и воплощения.

Соответственно, психолого-педагогическое сопровождение семьи, желающей взять на воспитание из детского дома ребенка с OB3, должно происходить во всех трех ракурсах.

Ребенок-сирота и специфика его самоидентификации

Ощущение сиротства - тяжелое бремя для ребенка, которое сопровождает его всю последующую жизнь. Его особенно травмирует осознание того, что он «ничей». Такая идентификация очень устойчива и восприимчива к малопривлекательным прогнозам будущего, что дополняется отклонениями в состоянии здоровья и психологическом развитии ребенка-сироты. Мир вне интернатных учреждений и манит его к себе своей новизной, и одновременно страшит своей неизвестностью. Нередко исходом такой ситуации является стагнация. Отсюда следует стигматизированная самоидентификация себя как ребенка-сироты, замыкание в своем кругу, стремление к себе подобным. Дети-сироты живут как особая общность со специфическим ощущением чувства «мы», что порождает противопоставление себя контактной широкой и многоликой - социальной среде («они»).

Дети-сироты и дети-отказники нередко вынуждены смириться с тем, что они не просто «ничьи», они - «ненужные». Особую тяжесть своей «ненужности» испытывают дети-сироты с ограниченными возможностями здоровья, с инвалидностью. И таких детей среди сирот немало. Очевидно, что такая социальная ситуация приводит к искажениям личностного развития, деформациям характера, уплощению и нестабильности эмоциональной сферы, деструктивным жизненным позициям и пр. 
Проанализировав результаты ${ }^{*}$, полученные еще в 2011 году при использовании методики К. Леонгарда на определение акцентуаций характера, установлено следующее. У подростков из детского дома ярче всего выражены застревающие (занудливость, неразговорчивость, обидчивость), демонстративные (жажда власти и похвалы, склонность к интригам, эгоистичность), эмотивные (предпочитают общение в узком кругу, сострадательность, исполнительность, слезливость), циклотимные (нестабильное настроение), экзальтированные (словоохотливость, привязанность к близким, паникерство) акцентуации. То есть характерной особенностью детей-сирот является замкнутость и направленность на себя. Именно такой ребенок перемещается (извлекается) из закрытого сиротского, но своего круга в домашнюю - манящую и пугающую одновременно - чужую среду. Он тоже имеет свои опасения, надежды и ожидания. Соответственно, ключевая трудность связана с изменением самоидентификации ребенка-сироты. Психолого-педагогическое сопровождение необходимо выстраивать в направлении создания и обеспечения условий для мягкого разрушения его стигматизированного сиротского статуса и постепенного обретения им статуса домашнего ребенка. Главная задача при психолого-педагогической поддержке специалистами приемной семьи - сделать ребенка своим.

Таким образом, в момент усыновления напряженность испытывают обе стороны: и взрослые, и дети. Правда, предполагается, что взрослые старше, мудрее, опытнее и терпимее, чем дети. К тому же вспомним, что речь идет о ребенке с особыми потребностями. Как же могут складываться детско-родительские отношения в новой пока еще чужой для ребенка семье?

\section{Ребенок с ОВЗ и его семья}

Детско-родительские отношения в семьях, воспитывающих приемного ребенка с ОВ3, подчиняются общим психологическим закономерностям межличностного взаимодействия, однако их реализация опосредуется действием специфических факторов, связанных как с личностными особенностями и установками замещающих родителей, так и со своеобразием стилей воспитания такого ребенка.

Проблематика детско-родительских отношений в таких семьях в настоящее время проявляется острее, потому что обнаруживается операциональная неготовность субъектов семейной системы к гармоническому построению детско-родительских отношений. Очевидно, что в приемной семье наличие такой проблемы может создавать не просто сложную внутрисемейную ситуацию, но и порождать кризисное состояние и опасную дезорганизацию всей семейной системы [2].

\footnotetext{
* Сбор материалов осуществлен студенткой МГППУ М.Е. Прокопьевой, руководитель исследовательского проекта - Л.Б. Шнейдер.
} 
Установлено*, что при появлении ребенка с ОВ3 в кровной (биологической) семье в ней изменяются отношения супругов друг к другу: у женщин внимание к спутнику жизни уменьшается в 4 раза, у мужчин - в 2 раза. В супружеских отношениях прослеживается отдаление супругов друг от друга после рождения ребенка с ограниченными возможностями. Некоторые из них ищут «утешения» в обществе других членов семьи - здоровых детей и родственников.

Стоит вспомнить, что воспитание - это всегда проекция супружеских отношений [3]. Детско-родительские отношения тесно связаны с характером взаимоотношений между самими супругами, их образом жизни. Соответственно, родительская сплоченность благоприятна для развития и воспитания ребенка с OB3, a разобщенность - нежелательна. Очевидно, что целевая ориентация психолого-педагогического сопровождения должна быть сконцентрирована на процессах семейной интеграции и объединении усилий всех членов семьи ребенка с ОВЗ. Прежде всего это касается самих супругов - родителей такого ребенка.

У матерей после рождения особого ребенка практически все внимание смещается на него (73 \% случаев), у отцов такая центрация на начальном этапе менее заметна. Однако у них со временем отношения с ребенком улучшаются, а у матерей по мере взросления ребенка сами воспитательные интересы и степень воздействия на него несколько ослабляются. По-видимому, существенное значение имеет способность родителей к временной самоорганизации.

Полученные с помощью методики PARI данные показывают, что у мужчин и женщин, воспитывающих ребенка с OB3, примерно одинаковая включенность в семейные роли. Однако отношение к семейной роли у всех в той или иной мере различно. Для матерей характерна чрезмерная забота о ребенке. У отцов более выражено стремление ускорить его развитие. Следовательно, для осуществления успешного воспитательного процесса материнская забота должна сочетаться с отцовскими воспитательными установками.

Были также получены результаты, говорящие о том, что достаточно большое количество женщин (более 70 \%) ощущают ограниченность своих интересов исключительно рамками семьи, все их заботы сосредотачиваются на ней. На этом фоне отвержения ребенка с

\footnotetext{
* В исследовании (2020 г.) приняли участие 81 человек (30 детей с синдромом Дауна и 51 взрослый: родные отцы - 21 человек, биологические матери - 30 человек). Средний возраст детей составил 9 лет, родителей - 38 лет. Использованы следующие методики: социограмма «Моя семья» (модификация В.В. Ткачёвой), методика изучения родительских установок (parental attitude research instrument, PARI) E.C. Шефер и Р.К. Белл, адаптирована Т.В. Нещерет, и опросник детско-родительских отношений А.Я. Варги и В.В. Столина. Сбор материалов осуществлен Е. Борисовой, общее руководство исследованием - Л.Б. Шнейдер.
} 
OB3 не выявлено ни у одного родителя. Положительное отношение к нему демонстрируют практически все матери и более половины отцов. Однако стремление к сотрудничеству с ребенком присутствует только у половины матерей и отцов, другая половина демонстрирует нейтральное отношение к нему. Полностью отсутствие к сотрудничеству с ребенком выявлено у 4 \% отцов.

Близость с таким ребенком наблюдается также далеко не у всех матерей и отцов (14-20\%). Иногда в детско-родительских отношениях проскальзывает излишний авторитаризм, когда родители ведут себя слишком строго по отношению к ребенку, требуя от него послушания и задавая строгие дисциплинарные рамки. «Маленьким неудачником» ребенка считают $10 \%$ отцов. Однако большое число матерей и отцов убеждены, что неудачи ребенка случайны, и верят в него и его успешную судьбу.

Очевидно, что к вкладу матери и отца в воспитание ребенка с OB3 нельзя подойти с простым количественным замером. Педагогическая эффективность родительского влияния существенно зависит от функционально-ролевой структуры семьи, системы доверительных отношений взрослых членов семьи друг к другу и ребенку, от воспитательного потенциала и педагогической компетентности семьи в целом [3].

Таким образом, даже в отношениях с родным ребенком у биологических родителей возникает немало трудностей: во-первых, нелегко устоять и не распасться самой супружеской чете; во-вторых, в семейной системе обнаруживается функционально-ролевая асимметрия; в-третьих, возникают проблемы с полным принятием ребенка с ОВ3 и реализацией близости и сотрудничества с ним. Построение адекватных отношений с таким ребенком наиболее обременительно для отцов. Можно предположить, что аналогичные затруднения поджидают и приемную семью, что естественно актуализирует необходимость её психолого-педагогического сопровождения.

Успешность социально-психологической адаптации детей с OB3 в приемной семье зависит не только от адекватности детскородительских отношений, но и от общих условий жизнедеятельности семьи и её материально-бытовых, финансовых, жилищных проблем, способов получения и организации медицинского и социальнобытового обслуживания, а также от возможностей семьи по реабилитации и обучению такого ребенка.

Отношение родителей к ребенку с ОВ3 в приемной семье, являясь в целом положительным, может фундироваться тяжестью его физических нарушений и проявлений нездоровья, обнаруживать при этом определенные признаки напряженности в зависимости от родительских установок и воспитательной компетентности приемной семьи.

Раскрывая роль физических нарушений в психическом развитии

$$
-83-
$$


ребенка, рассмотрим их на примере детей дошкольного возраста с детским церебральным параличом. Изучение и сравнение между собой результатов здоровых детей и детей с отклонениями и затруднениями в двигательной активности показало, что дети без OB3 демонстрируют отдельные когнитивные показатели, превышающие результаты дошкольников с ОВ3 [1].

Однако дети с ОВ3 могут показать и демонстрируют, по нашим данным*, более высокие результаты по психоэмоциональному состоянию, общему умственному развитию, наглядно-образному мышлению и зрительно-двигательной координации, чем их здоровые сверстники. При этом показатели кратковременной памяти (запоминание слов, предметов и движений) у них очень низкие [6]. Также отмечается слабость активного внимания, невысокий уровень действий с сенсорными эталонами, операций сравнения и классификации, из-за чего расстраиваются различные звенья пространственного и временного восприятия.

Итак, нарушения двигательной активности затрудняют познавательное развитие детей-дошкольников (памяти, внимания, восприятия, отдельных компонентов познавательной активности), но не блокируют его окончательно. При компенсирующих условиях и положительном эмоциональном состоянии их общее умственное развитие не является ущербным [1]. Значительную роль в таких случаях играет помощь соответствующих специалистов (дефектологов, медицинского персонала, психологов, педагогов, массажистов и пр.).

Таким образом, специфика физических нарушений особым образом обуславливает психическое развитие ребенка с ОВЗ. Как видно уже на примере детей с ДЦП, наряду с двигательной патологией обнаруживаются сохранные области психического развития, которые могут стать отправными точками для организации грамотных психолого-педагогических воздействий приемных родителей.

Воспитание приемного ребенка с ОВЗ в замещающей семье

В реализации воспитательных усилий возможно использование разнообразия направлений и форм взаимодействия замещающих родителей с особым ребенком и их сотрудничество с компетентными специалистами. В связи с этим в психолого-педагогическом сопровождении такой семьи уместно прибегать к игровой деятельности, соответствующей возрасту ребенка с OB3 и помогающей развивать его общие и специальные способности через разнообразные виды игр. Отдельное внимание следует уделять развитию потребности ребенка в познании и самопознании, его способности к сотрудничеству,

\footnotetext{
* Исследование проведено в 2011 году аспиранткой П.А. Козинцевой под общим руководством Л.Б. Шнейдер.
} 
Вестник ТвГУ. Серия "Педагогика и психология". 2020. № 3(52)

соучастию и сопереживанию. Не меньшего внимания заслуживает культурно-гигиеническое воспитание, ориентированное на развитие жизненно важных культурно-гигиенических навыков и умений в процессе выполнения режимных моментов.

Еще одним важным направлением сопровождения приемной семьи, воспитывающей ребенка с OB3, является физкультурнооздоровительная работа, направленная на формирование и поддержание здорового образа жизни.

В воспитании приемного ребенка большое значение имеют семейные традиции, которые должны (и могут) формировать доброжелательные отношения между всеми членами семьи, развивать умение получать удовольствие от внутрисемейного общения и досуга. Не обойтись в воспитании приемного ребенка без его приучения к посильному (возможному?) труду и трудовой деятельности, без которых невозможно формирование практических навыков.

Таким образом, данные направления определяют стратегию развития системы воспитания в приемной семье и её психологопедагогического сопровождения. В целом они аналогичны воспитательным воздействиям на ребенка с OB3 в биологической семье. В них явно проступает педагогическая центрация на здоровье ребенка, что довольно понятно, так как без реабилитационных мероприятий в данном случае не обойтись.

При этом компетентное родительство, на наш взгляд, проявляется тогда, когда родитель действует СПОКОЙНО (без криков и истерик), ВДУМЧИВО (значит с умом, иногда с выдумкой), РЕАЛИСТИЧНО (с учетом возраста, здоровья (или его ограничений) и пристрастий ребенка), ЭФФЕКТИВНО (с подведением итогов и осмыслением результатов) [4].

При этом компетентный родитель придерживается рациональных педагогических установок, помогает детям почувствовать, что их ценят, поддерживают, уважают, что они на многое способны и ими гордятся. Родительская вера наделяет ребенка ответственностью в большей степени, чем все инструкции и предписания, вместе взятые [4].

Реализуя психолого-педагогическое воздействие на ребенка, каждый родитель осознает, что мгновенных результатов в воспитании и обучении ребенка ждать не стоит, а родитель, воспитывающий ребенка с OB3, рано или поздно понимает, что даже минимальные результаты требуют больших как временны́х, так и энергетических усилий и терпения.

От стигматизации нездоровья к новым ичелевым ориентациям в воспитании ребенка с ОВЗ

Ребенка с ограниченными возможностями здоровья при использовании всех медицинских и реабилитационных мер не всегда можно вылечить, но это не значит, что он однозначно несчастлив, лишен возможности быть счастливым. Нередко здоровые люди 
воспринимают ребенка с ОВ3 как объект жалости, снисходительного внимания и помощи, что психологически инвалидизирует его, закрывает перед ним возможные источники счастья, акцентируя факт нездоровья как детерминанту его бытия [5]. Его самоидентификация сводится к самовосприятию себя как больного ребенка. Это приводит к сужению и деформации образа счастья и образа мира для детей с ОВ3. Очевидно, что в осуществлении психолого-педагогического сопровождения семьи, воспитывающей ребенка с OB3, нужна переориентация родительских установок.

При восприятии ребенка с ОВ3 как неполноценного, слабого часто возникает неоправданное ограничение рамок его жизнедеятельности: нормальная жизнь вроде бы ему вовсе недоступна, так как «здоровье не то», «многим обделен» и пр. Отказ от жалостливой стигматизации психологически расширяет рамки восприятия, позволяя ставить продуктивные педагогические вопросы: для чего, каких форм творчества, любви данный - ограниченный - уровень здоровья достаточен? Какие пути к счастью открыты детям с ОВ3? [5].

В логике реализации психолого-педагогического сопровождения такому ребенку надо помочь обнаружить источники счастья как сопричастности к миру. Например, такие: миропостижение, то есть поиск, открытие и совершенствование каналов восприятия, способствующих созерцанию, осмыслению и «вбиранию в себя» мира; участие в жизни через включение в сферу живых эмоций, развитие сопереживания, со-радования; участие в жизни через любовь и творчество.

Эти задатки есть абсолютно у каждого, вопросы о качестве, уровне, содержательной насыщенности вторичны [5].

Переориентация родительских установок требует от каждого родителя, воспитывающего ребенка с ОВЗ компетентности в вопросах: повышения ответственности за свое поведение и свою жизнь; развития готовности к творческому реагированию на физическое нездоровье и поведенческие проявления ребенка; веры в себя, близких людей и «прекрасное далеко», созидаемое сейчас; готовности научиться понимать своего ребенка лучше, чем он сам себя понимает; умения сохранять любовь и доверие к ребенку; постоянного анализа опыта своих удач и ошибок; постоянного поиска и обнаружения новой информации по проблеме реабилитации и воспитания ребенка с определенным видом ОВ3; изменения реакции на любую возникающую проблему (от поиска причин к поиску решений); повышения сензитивной наблюдательности; поиска союзников, готовых помочь; осознания и понимания детского физического нездоровья в контексте более широкого круга семейных задач.

Очевидно, что самим родителям трудно справиться с такими задачами. Большую роль в устройстве ребенка с ОВ3 в приемную семью, его принятии всеми членами семьи и включении его в 
домашнюю среду играет процесс психолого-педагогического сопровождения подобных семей. Основная цель такого сопровождения - интеграция социальной, медицинской и психолого-педагогической реабилитации, повышение общего воспитательного потенциала семьи и улучшения качества жизни ребенка с OB3.

\title{
Список литературы
}

1. Козинцева П.А. Особенности и психосоциальные факторы познавательного развития младших дошкольников: автореф. дис. ... канд. психол. наук. М., 2011. 25 с.

2. Шнейдер Л.Б. Повышение компетентности родителей в реализации функциональноролевого потенциала семьи и преодолении кризисных состояний: программа и учеб.-метод. пособие. М.: ФГНУ «Институт социальной педагогики» РАО, 2013. 244 с.

3. Шнейдер Л.Б. Семья: оглядываясь вперед. СПб.: Питер, 2013. 368 с.

4. Шнейдер Л.Б., Зыкова М.Н. Компетентное родительство. М., МПСУ, 2018. 126 с.

5. Шнейдер Л.Б., Зыкова М.Н. Педагогический труд как источник стресса и поддерживающий ресурс // Вестн. ГОУ ДПО ТО «ИПК и ППРО ТО». Тульское образовательное пространство. 2020. № 1. С. 64-71.

6. Schnejder L.B., Kozintseva P.A. The specificity and psycho-social context of cognitive development of young preschoolers// Компетенције васпитача за друштво знања: тематски зборник / Четврта међународна научностручна конференција Методички дани 2015, [Кикинда, 30. мај 2015]; [организатори] Висока школа струковних студија за образовање васпитача у Кикинди ... [и др.]; [уредник Тамара Грујић, Јасмина Арсенијевић; превод Тања Бркљач]. Кикинда: Висока школа струковних студија за образовање васпитача, 2017. С. 345.

Об авторе:

ШНЕЙДЕР Лидия Бернгардовна - доктор психологических наук, профессор кафедры психологической антропологии, Московский государственный педагогический университет (ФГБОУ ВО МГПУ), Москва, Россия, ORCID: https://orcid.org/0000-0002-3517-0873; e-mail: lshnejder@yandex.ru

\section{A CHILD WITH DISABILITIES IN FOSTER CARE: FEATURES OF PSYCHOLOGICAL AND PEDAGOGICAL SUPPORT}

\section{L.B. Shneyder}

\author{
Moscow State Pedagogical University, Moscow
}

The article discusses the issues of placing a child in a foster family, accompanied by a change in his status, decentralizing the perception of himself as an orphan child and gaining a new identity as a home child. The process of adopting a child is seen as a period of fears, hopes, expectations and illusions. It is emphasized that the essence of psychological and pedagogical support of a child is the need to shift the attention of the substitute family (its pedagogical orientation) from the fact of the adopted child's limited health opportunities (HIA), from a "pitiful" and disabling attitude to him to creating conditions for raising him as a happy person. The author reveals the concept of a competent version of parenthood.

Keywords: child, orphan, ill-health, the foster family, difficulties, hopes and happiness. 